\title{
WORK INCENTIVES AND SALARY DISTRIBUTIONS \\ IN MAJOR LEAGUE BASEBALL
}

\author{
by
}

Brandon M. Avrutin and Paul M. Sommers

September 2006

MIDDLEBURY COLLEGE ECONOMICS DISCUSSION PAPER NO. 06-10

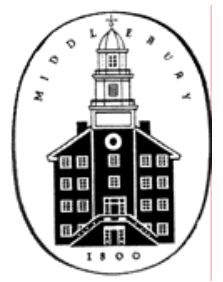

DEPARTMENT OF ECONOMICS

MIDDLEBURY COLLEGE

MIDDLEBURY, VERMONT 05753

http://www.middlebury.edu/ econ 


\title{
WORK INCENTIVES AND SALARY DISTRIBUTIONS IN MAJOR LEAGUE BASEBALL
}

\author{
by \\ Brandon M. Avrutin and Paul M. Sommers \\ Department of Economics \\ Middlebury College \\ Middlebury, Vermont 05753
}

JEL \#: J41 


\section{WORK INCENTIVES AND SALARY DISTRIBUTIONS \\ IN MAJOR LEAGUE BASEBALL}

Baseball fans complain about the extraordinary sums of money team owners spend to sign free agents. The size of these superstar contracts may not only anger veterans on the team, but adversely affect overall team performance. [See, for example, F. Wiseman and S. Chatterjee (2003), “Team Payroll and Team Performance in Major League Baseball: 1985-2002,”

Economics Bulletin, 1(2), pp. 1-10.] This note reexamines the relationship between payroll and performance in Major League Baseball (MLB) from 2001 to 2005. Specifically, is there still empirical support for the Wiseman and Chatterjee claim that the more equally this payroll is distributed among team members, the better the on-field performance of the team.

To determine whether or not the structure of compensation has any effect on performance, Gini coefficients were calculated for all 30 teams in MLB from 2001 to 2005. Player salary data are from www.rodneyfort.com/PHSportsEcon/Common/OtherData/DataDirectory.html . The larger a team's Gini coefficient, the more unequal is the salary distribution. A Gini coefficient of 1 would represent complete inequality (one player earns all of the team's payroll) and a Gini coefficient of 0 would represent complete equality of the salary distribution.

For each of the five years, the team's win percentage was first regressed on the team's Gini ratio. The regression results for 2005 were as follows ( $t$-values in parentheses):

$$
\text { WINPCT }=.320+.324 \text { GINI }
$$

$$
\mathrm{R}^{2}=.316
$$

The regression results for 2001 through 2004 (with one exception) likewise show that the greater the Gini ratio (that is, the more unequally the team payroll is distributed), the better the on-field performance of the team. When team payroll is added to each year's regression, neither the Gini coefficient nor team payroll is significant at better than the .05 level, again with one exception. 
For the 2003 season, when the single observation for the New York Yankees is excluded (that is, the year before the Yankees acquired Alex Rodriguez and thereafter skewed the distribution of this team's player salaries), both team payroll and the Gini are again not statistically significant.

The most striking result about these regressions is the collinearity between, first, the Gini coefficient and team payroll and, second, the Gini coefficient and win percentage. In 2005, the top two Gini coefficients belonged to the New York Yankees and the Boston Red Sox (both with .586 win percentages); the bottom two Gini coefficients belonged to the Colorado Rockies and the Kansas City Royals (with win percentages of .414 and .346, respectively). In general, one can conclude that for the 2001-2005 period more equal salary distributions in MLB do not lead to better on-field performance. 